\author{
Brief article
}

\title{
Do transposed-letter similarity effects occur at a morpheme level? Evidence for morpho-orthographic decomposition
}

\author{
Jon Andoni Duñabeitia ${ }^{\mathrm{a}, \mathrm{c}, *}$, Manuel Perea ${ }^{\mathrm{b}}$, Manuel Carreiras ${ }^{\mathrm{a}, \mathrm{c}}$ \\ ${ }^{a}$ Universidad de La Laguna, Departamento de Psicología Cognitiva, 38205 Tenerife, Spain \\ ${ }^{\mathrm{b}}$ Universitat de València, Spain \\ ${ }^{\mathrm{c}}$ Instituto de Tecnologías Biomédicas, Universidad de La Laguna, 38207 La Laguna, \\ Santa Cruz De Tenerife, Spain
}

Received 2 June 2006; revised 17 October 2006; accepted 1 December 2006

\begin{abstract}
When does morphological decomposition occur in visual word recognition? An increasing body of evidence suggests the presence of early morphological processing. The present work investigates this issue via an orthographic similarity manipulation. Three masked priming lexical decision experiments were conducted to examine the transposed-letter similarity effect (e.g., jugde facilitates JUDGE more than the control jupbe) in polymorphemic and monomorphemic words. If morphological decomposition occurs at early stages of visual word recognition, we would expect an interaction with transposed-letter effects. Experiment 1 was carried out in Basque, which is an agglutinative language. The nonword primes were created by transposing two letters that either crossed the morphological boundaries of suffixes or did not. Results showed a transposed-letter effect for non-affixed words, whereas there were no signs of a transposed-letter effect across morpheme boundaries for affixed words. In Experiment 2, this issue was revisited in a non-agglutinative language (Spanish), with prefixed and suffixed word pairs. Again, results showed a significant transposed-letter effect for non-affixed words, whereas there were no signs of a transposed-letter effect across morpheme boundaries for affixed words (both prefixed words and suffixed words). Experiment 3 replicated the previous findings, and also revealed that, for polymorphemic words,
\end{abstract}

\footnotetext{
* Corresponding author. Tel.: +34 922 317515; fax: +34 922317461.

E-mail address: jaduna@ull.es (J.A. Duñabeitia).
} 
transposed-letter priming effects occurred for within-morpheme transpositions. Taken together, these findings support the view that morphological decomposition operates at an early stage of visual word recognition.

(C) 2006 Elsevier B.V. All rights reserved.

Keywords: Visual word recognition; Morphology; Lexical access; Letter transpositions

\section{Introduction}

The role of morphological information during visual word recognition is a controversial area in which there is lively debate about the processing stage at which morphological decomposition occurs. Although there is some empirical evidence that favors morphological decomposition at a late stage, operating over semantic processes (e.g., Giraudo \& Grainger, 2001, 2003; Marslen-Wilson, Tyler, Waksler, \& Older, 1994; Plaut \& Gonnerman, 2000), there is an increasing body of evidence pointing to an earlier processing of morphological units, related to automatic processes in the access to orthographical representations (Christianson, Johnson, \& Rayner, 2005; Rastle \& Davis, 2003; Rastle, Davis, \& New, 2004; Rastle, Davis, Tyler, \& Marslen-Wilson, 2000; Taft, 1994).

One key study favoring early morphological decomposition is the recent work of Rastle and colleagues (2004), using a masked priming lexical decision task. They found a similar priming effect (relative to an unrelated condition) for prime-target pairs matched by morphological derivations of the same root (walker-WALK) and for pairs with a pseudo-morphological relation that could be decomposed in root + suffix (corner-CORN), whereas they failed to find a priming effect for primetarget pairs with a purely orthographical relation (brothel-BROTH). ${ }^{1}$ One important aspect of this paper is that it demonstrates that morphological units engage an early orthographical level of word recognition, even if they do not correspond to real morphemes in a given word (i.e., the case of the pseudo-morpheme-er in corner). The fact that words preceded by masked primes sharing either semantically transparent or apparent morphological relationships with the targets resulted in similar priming effects is a highly relevant finding for models of word recognition. This mainly structural facilitation does not fit into the semantically based decomposition accounts proposed by localist (e.g., Giraudo \& Grainger, 2001) and connectionist models (e.g., Plaut \& Gonnerman, 2000). Instead, it points in the direction of models that claim for a blind-to-semantics morphological decomposition (e.g., the interactive-activation account described by Taft, 1994).

If morphological decomposition occurs at early pre-lexical stages of visual word recognition, coinciding with other low-level processes such as letter position

\footnotetext{
${ }^{1}$ Rastle et al. (2004) employed three different types of prime-target pairs: (1) a morphological relationship, by using suffixed primes (e.g., walker-WALK), (2) a pseudo-morphological relationship, designing primes ending in letters that could be a legal suffix (e.g., corner-CORN), and (3) a purely orthographical relationship, where the final letters could not be a morpheme (e.g., brothel-BROTH).
} 
encoding, then orthographical effects, such as the transposed-letter similarity effect (i.e., longer responses times for jupbe-JUDGE than for jugde-JUDGE; see Perea \& Lupker, 2003a, 2003b, 2004; see also Andrews, 1996; Christianson et al., 2005; Perea \& Carreiras, 2006a, 2006b; Schoonbaert \& Grainger, 2004), ${ }^{2}$ should interact with morphological effects. Note that models of late morphological processing (Giraudo \& Grainger, 2001) would predict that early orthographic effects would not interact with morphological effects because they occur at different processing stages. In line with the claim that orthography and morphology belong to different stages, several recently proposed computational models of the letter encoding process (SOLAR model: Davis, 1999; Overlap model: Gómez, Ratcliff, $\&$ Perea, submitted for publication) also place the assignment of letter position before morphological decomposition. Accordingly, the transposed-letter effect should not vary for transpositions occurring across or within morphemes (see Perea \& Carreiras, 2006a; for details). Consistent with this view, Perea and Carreiras (2006a) found that the transposed-letter effect across lexeme boundaries for compound words (e.g., arbigide-ARGIBIDE vs. arkipide-ARGIBIDE; $28 \mathrm{~ms}$; $A R G I B I D E$ is a compound of $A R G I+B I D E)$ was similar to the transposed-letter effect with non-compound words (ortakila-ORKATILA vs. orbahila-ORKATILA; $31 \mathrm{~ms})$.

Nonetheless, the presence of a transposition-priming effect across lexeme boundaries for compound words in the Perea and Carreiras (2006a) experiment could be due to the fact that there were no cues that marked the lexeme boundary, and hence the cognitive system had no means of knowing where the lexeme boundaries stood. A stronger case would be made by transposing the morpheme boundaries of affixed words. In this line, Christianson et al. (2005; Experiment 3) addressed the issue of derivational morphology in a naming experiment using a masked priming paradigm, employing exclusively the English suffix -er (e.g., adapter, boaster) and manipulating letter transposition across morphemes (e.g., adapetr, boasetr). They compared this effect to the transposed-letter effect derived from pseudo-suffixed words carrying the word-final -er bigram (e.g., bluster, lobster), which do not contain a legal stem (e.g., blust- and lobs- are not stems). Christianson et al. found a significant transposed-letter effect for within-morpheme transpositions (e.g., blusetr-BLUSTER vs. blusler-BLUSTER), but not for between-morpheme transpositions (boasetr-BOASTER vs. boasler-BOASTER). There were two limitations in that experiment, however: (i) the critical interaction was not significant and (ii) the stimulus set was small and constrained to a single suffix (12 suffixed and 12 pseudo-suffixed pairs, always with the same ending: -er). Although the evidence was suggestive, it cannot be taken as conclusive. In order to draw firm conclusions regarding the pre-lexical processing of derivational morphology, it is necessary to test a larger variety of affixes (both prefixes and suffixes) and to employ a larger number of items per condition. This is one of the

\footnotetext{
2 The presence of transposed-letter effects falsifies the "channel-specific" coding scheme employed by a number of influential computational models of visual word recognition (e.g., McClelland \& Rumelhart, 1981; see also Coltheart, Rastle, Perry, Ziegler, \& Langdon, 2001; Grainger \& Jacobs, 1996).
} 
aims of the current study, extending over discrepancies on whether the processing of prefixes and suffixes may differ (e.g., Colé, Beauvillain, \& Segui, 1989; Meunier $\&$ Segui, 1999). A second goal is to examine whether or not the alleged morphoorthographic decomposition is language-independent. To that end, we examine transposed-letters effects across and whiting morphemes in two languages that differ widely in their morphology: Spanish and Basque. Spanish follows the morphological rules of Romance languages, whereas Basque - as a pre-Indo-European language - has a very different morphological structure, based on morpheme agglutination at the end of the root (see Perea et al., in press, or Laka, 1989, for a brief description of the Basque language). Indeed, there is empirical evidence that shows some differences in the magnitude of masked morphological priming in these two languages (Carreiras, Duñabeitia, \& Perea, submitted for publication).

In summary, this study addresses the processing of orthographic and morphological units in the pre-lexical stage of visual word recognition. Specifically, we examine whether or not the transposed-letter priming effect remains facilitative across an affix's morphemic boundaries. If the transposed-letter priming effect vanishes for transpositions across morphemes, this would provide compelling evidence for early, pre-lexical morphological decomposition, and this would have critical implications for models of visual word recognition. Experiment 1 was carried out in Basque, and Experiments 2 and 3 were carried out in Spanish.

\section{Experiment 1 (Basque experiment)}

\subsection{Method}

\subsubsection{Participants}

Thirty-six undergraduate and graduate students from the University of the Basque Country and the University of Deusto received $2 €$ each for taking part in this experiment. All of them had normal or corrected-to-normal vision and were native speakers of Basque. They had Basque as their learning language in school and college.

\subsubsection{Materials}

The targets were 40 Basque suffixed words of 6-10 letters [mean word frequency per one million words in Perea et al., in press, count, 38; range, 1-205; mean word length, 8.02; and mean number of orthographic neighbors $(N), 1.5]$, and 40 nonaffixed Basque words, equivalent to the first set in length, word frequency and orthographic neighbors (mean word frequency per one million words, 37; range, 1-205; mean word length, 8.02; and mean $N, 1.9)$. The affixed targets were presented in uppercase and were preceded by primes in lowercase that were (1) the same as the target except for a transposition of the last letter of the lemma and the initial letter of the morpheme (transposed-letter, across the morphemic boundary), txapedlun-TXAPELDUN (winenr-WINNER) and (2) the same as the target except for the substitution of the two adjacent letters involved in the across-morphemic transposition, txapebtun-TXAPELDUN (winasr-WINNER). A parallel procedure was followed for 
pairing the 40 non-affixed targets (e.g., txapnona-TXANPONA for the transposedletter pairs, and txagsona-TXANPONA for the letter replacement pair, where txanpona is the Basque for coin: cion-COIN for the transposed, and cuen-COIN for the replaced condition), maintaining both the transposed and the replaced letters in the same location of the letter string as in the suffixed condition. The primes were always nonwords. The frequency of the critical (manipulated) bigram was matched across the prime conditions, $p>.88$, so that neither affixed and non-affixed items, nor the transposed and replaced primes differed in bigram frequency. An additional set of 80 nonwords matched to the words in length (mean nonword length, 8.0 and range, 610) was included for the purposes of the lexical decision task. The manipulation of the nonword trials was the same as that for the word trials. Two lists of materials were constructed so that each target appeared once in each list, but each time in a different priming condition (transposed-letter or replacement-letter). Different groups of participants were used for each list.

\subsubsection{Procedure}

The experiment was run individually in a quiet room. The stimuli presentation and data collection of the response times were run by using DMDX (Forster \& Forster, 2003) in a PC compatible computer with a CRT monitor. Each of the trials consisted in the 500-ms centered presentation of a forward mask of hash marks (\#'s), followed by the prime presentation in lowercase (12-pt. Courier New font) for $66 \mathrm{~ms}$, and the immediate centered appearance of the uppercased target stimulus. The participants had to press one of two labeled buttons on the keyboard in order to indicate the linguistic legality of the letter string presented in uppercase (' $M$ ' for words and ' $Z$ ' for nonwords). Participants were not informed of the presence of lowercase items. Participants reported no awareness of the lowercase stimuli when asked after the experiment. ${ }^{3}$ All the trials were randomized so that there was no trial order repetition across participants. Each participant received a total of 24 practice trials prior to the 160 experimental trials.

\subsection{Results and discussion}

The latency analysis excluded all data from incorrect responses ( $3.1 \%$ of words trials), as well as the percentage of responses beyond the $250-1500 \mathrm{~ms}$ cutoff ( $5 \%$ of data). The mean response latencies and percentages of error are presented in Table 1. Participant and item ANOVAs based on the participant and item response latencies and percentages of error were conducted based on a 2 (Type of word: affixed, non-affixed) $\times 2$ (Type of prime: transposed, replaced) $\times 2$ (List: list 1, list 2) design. List was incorporated in the ANOVAs to extract the variance of the error associated with the lists (Pollatsek \& Well, 1995). All significant effects had $p$ values less than .05 .

\footnotetext{
${ }^{3}$ Christianson et al. (2005) used a longer stimulus-onset asynchrony (around $100 \mathrm{~ms}$ ), than in the present experiments $(66 \mathrm{~ms})$. Although the employed SOA may be bordering conscious processing, participants reported no awareness of the prime stimuli.
} 
Table 1

Mean lexical decision times (in $\mathrm{ms}$ ) and percentage of errors (in parentheses) for word and nonword targets in Experiment 1

\begin{tabular}{llll}
\hline & \multicolumn{2}{l}{ Type of prime } & Priming \\
\cline { 2 - 3 } & Transposed-letter & Replaced-letter & \\
\hline Word trials & $765(1.5)$ & $751(1.8)$ & $-14(0.3)$ \\
$\quad$ Suffixed pairs & $780(3.3)$ & $816(6.1)$ & $36(2.8)$ \\
$\quad$ Non-suffixed pairs & $918(1.5)$ & $947(1.5)$ & $29(0.0)$ \\
Nonword trials & &
\end{tabular}

Word data. As the interaction between Type of word and Type of prime was significant, $F 1(1,34)=9.31, M S E=2457 ; F 2(1,76)=5.09, M S E=8553$. we conducted simple effect tests of affixed and non-affixed target words. These analyses showed that there was a robust transposed-letter effect for the non-affixed words $(36 \mathrm{~ms})$, $F 1(1,34)=9.57, M S E=2408 ; F 2(1,38)=4.90, M S E=8170$, whereas the transposedletter effect across morpheme boundaries for suffixed words was nonsignificant $(-14 \mathrm{~ms}), F 1(1,34)=1.58, M S E=2430 ; F 2(1,38)=1.01, M S E=8936$. The other effects were not significant.

The ANOVA on the error data showed that participants made more errors on targets preceded by a replacement-letter prime than on targets preceded by a transposed-letter prime, $F 1(1,34)=6.36, M S E=13 ; F 2(1,76)=2.33, M S E=40$. In addition, participants made more errors on non-affixed words than on affixed words, $F 1(1,34)=17.88, M S E=18 ; F 2(1,76)=8.42, M S E=44$. The other effects were not significant.

Nonword data. The latency analyses only showed an advantage of targets preceded by a transposed-letter prime relative to the targets preceded by a replacement-letter prime, $F 1(1,34)=11.27, M S E=1354 ; F 2(1,78)=7.77, M S E=4749$. The other effects were not significant.

The error data did not reveal any significant effects.

The results have shown the usual transposed-letter priming effect for non-affixed words relative to the control condition $(36 \mathrm{~ms}$; txapnona-TXANPONA vs. txagsona-TXANPONA; e.g., Perea \& Lupker, 2003a, 2004), whereas there were no signs of a transposed-letter priming effect across morpheme boundaries for affixed words (-14 ms; txapedlun-TXAPELDUN vs. txapebtun-TXAPELDUN). Thus, these data provide evidence for an orthographically based decomposition of derivational suffixed words.

The disappearance of the transposed-letter effect across morphemes (root + suffix) is clear-cut, suggesting the presence of pre-lexical morphological decomposition at the early stages of visual word recognition. There are two remaining issues: (i) whether this finding can be generalized to other derivational morphemes, such as prefixes and (ii) whether this finding with Basque suffixed words can be generalized to other languages. Experiment 2 was conducted in Spanish which, unlike Basque, contains a large number of prefixes and suffixes. 


\section{Experiment 2 (Spanish experiment)}

\subsection{Method}

\subsubsection{Participants}

Thirty-eight students of the University of La Laguna received course credit in exchange for taking part in the experiment. All of them had normal or corrected-tonormal vision and were native speakers of Spanish.

\subsubsection{Materials}

The target words were 88 affixed Spanish words (mean word frequency per one million words in Sebastián-Gallés, Martí, Carreiras, \& Cuetos, 2000; count, 8.96; range, 0.1-118; mean word length, 8; and mean $N, 0.5$ ) and 88 non-affixed words (mean word frequency, 8.93; range, 0.1-118; mean word length, 8; and mean $N, 0.3$ ). Half of the affixed targets were suffixed words, and half were prefixed words. The control and experimental pairs were manipulated in the same way as in Experiment 1 , preserving both replaced-letter shape and transposed- and replaced-letter position in the string for the affixed and the non-affixed words (the control word ESCOM$B R O$ could be primed by the transposed escobmro or the replaced escohcro; the prefixed word BIZNIETO, could be preceded by binzieto or by bicsieto; the suffixed word MESONERO could be primed by mesoenro or by mesoasro). The frequency of the critical (manipulated) bigram was matched across the prime conditions for the affixed and non-affixed words, both in the transposed and in the replaced conditions, $p>$.53. A set of 176 nonwords were included as nonword targets for the purposes of the lexical decision task, matched to the words in length (mean nonword length, 8); the manipulation of transposed- and replacement-letter primes was the same as that for word trials. Two lists were constructed and half of the participants received one, while the other half received the other.

\subsubsection{Procedure}

The same as in Experiment 1.

\subsection{Results and discussion}

For the analysis of the response times, data from incorrect responses $(6.9 \%)$ and latencies beyond the $250-1500 \mathrm{~ms}$ cutoff $(3.2 \%)$ were omitted. Mean response times and error rates are presented in Table 2. Participant and item ANOVAs based on the participant and item response latencies and percentages of error were conducted based on a 2 (Type of affix: suffix, prefix) $\times 2$ (Type of word: affixed, non-affixed) $\times 2$ (Type of prime: transposed, replaced) $\times 2$ (List: list 1 , list 2$)$ design.

Word data. The ANOVA on the latency data showed that affixed target words were responded to faster than non-affixed words in the analysis by participants, $F 1(1,36)=8.08, M S E=1250 ; F 2(1,168)=2.05, M S E=17270, p>.15$. But the relevant finding here was the significant interaction between Type of word and Type of prime, $F 1(1,36)=6.37, M S E=1580 ; F 2(1,168)=9.35, M S E=2179$. This interaction reflects 
Table 2

Mean lexical decision times (in $\mathrm{ms}$ ) and percentage of errors (in parentheses) for word and nonword targets in Experiment 2

\begin{tabular}{llll}
\hline & \multicolumn{2}{l}{ Type of prime } & Priming \\
\cline { 2 - 3 } & Transposed-letter & Replaced-letter & \\
\hline Word trials & $789(5.8)$ & $781(6.3)$ & $-8(0.5)$ \\
$\quad$ Prefixed pairs & $774(5.0)$ & $797(7.1)$ & $23(2.1)$ \\
Non-prefixed pairs & $740(5.7)$ & $742(4.7)$ & $2(-1.0)$ \\
$\quad$ Suffixed pairs & $755(9.4)$ & $772(11.2)$ & $17(1.8)$ \\
$\quad$ Non-suffixed pairs & $903(3.3)$ & $908(3.3)$ & $5(0.0)$ \\
\hline
\end{tabular}

a transposed-letter priming effect for the non-affixed words $(20 \mathrm{~ms}), F 1(1,36)=5.82$, $M S E=2629 ; F 2(1,84)=12.32, M S E=2438 ;$ in contrast, the transposed-letter priming effect across morpheme boundaries for affixed words was negligible $(-3 \mathrm{~ms})$, both $F_{\mathrm{S}}<1$. This pattern occurred for both prefixed and suffixed words, as revealed by the lack of an interaction between Type of word, Type of prime, and Type of affix, both $F$ s $<1$ (see Table 2). The other effects were not significant.

The ANOVAs on the error rates showed that participants made more errors on non-affixed words than on affixed words, $F 1(1,36)=14.17, M S E=34 ; F 2(1,168)=$ $25.73, M S E=166$. The other effects were not significant.

Nonword data. None of the effects was significant.

As in Experiment 1, the results showed that transposed-letter primes facilitate recognition of the targets more than the replacement-letter primes, but only when the transposition did not cross the morpheme boundaries. No signs of a transposed-letter priming effect were observed when the transposition crossed the morpheme boundaries: neither for prefixed words $(-8 \mathrm{~ms})$ nor suffixed words $(2 \mathrm{~ms})$. Thus, the present results extend the results from Experiment 1 to the processing of prefixes and suffixes in a non-agglutinative language (Spanish) -i.e., it is consistent with the view that morpho-orthographic decomposition is language-independent.

There is one caveat, however. Although transposed-letter priming effects with monomorphemic words are well documented (e.g., see Forster et al., 1987; Perea \& Lupker, 2003a, 2003b, 2004), there is the possibility that these effects might interact with other factors affecting the recognition of monomorphemic and polymorphemic words.

Thus, in order for the present findings to be completely compelling, it is necessary to demonstrate that transposed-letter priming occurs for within-morpheme manipulations but not for between-morpheme manipulations in the same set of prefixed and suffixed words. ${ }^{4}$ This is precisely the aim of Experiment 3. Experiment 3 was a replication of Experiment 2, except that it included not only acrossmorpheme transpositions (as in Experiments 1 and 2), but also within-morpheme transpositions.

\footnotetext{
${ }^{4}$ We thank an anonymous reviewer for suggesting this experiment.
} 


\section{Experiment 3 (Spanish experiment: across vs. within morpheme transpositions)}

\subsection{Method}

\subsubsection{Participants}

Thirty-two students from the University of La Laguna took part in this experiment in exchange for course credit. All of them were native speakers of Spanish. None of them had participated in Experiment 2.

\subsubsection{Materials}

The same set of 88 affixed Spanish words from Experiment 2 was used. Half of these were suffixed words, and the other half were prefixed words. Besides the experimental conditions of Experiment 2, we added a transposition/replacement of letters within the stem of the words. Consequently, each of the affixed targets could be preceded by four different primes that were: (i) a transposed-letter nonword created by transposing two adjacent letters across the morphemic boundary (e.g., the suffixed target word MESONERO preceded by the prime mesoenro), (ii) a replacement-letter nonword created by replacing two adjacent letters across the morphemic boundary (mesoasro-MESONERO), (iii) a transposed-letter nonword created by transposing two adjacent letters within the stem (meosnero-MESONERO), or (iv) a replacementletter nonword created by replacing two adjacent letters within the stem (meurnero$M E S O N E R O$ ). The frequency of the critical (manipulated) bigrams was matched across the prime conditions, $p>.50$. As in Experiment 2, a set of 88 nonwords was included as targets for the purposes of the lexical decision task. The manipulation for the nonword targets was the same as for the word targets. Four lists were created, so that each affixed target word appeared only once in each list, each time preceded by a different prime condition.

\subsubsection{Procedure}

The procedure was the same as in Experiments 1 and 2.

\subsection{Results and discussion}

Incorrect responses to word trials $(4.1 \%)$ and latencies beyond the $250-1500 \mathrm{~ms}$ cutoff $(3.1 \%)$ were omitted from the analyses. Mean response times and error rates are presented in Table 3. Participant and item ANOVAs for the response latencies and percentages of error were conducted based on a 2 (Type of affix: suffix, prefix) $\times 2$ (Position of manipulation: within morpheme boundaries, across morpheme boundaries) $\times 2$ (Type of prime: transposed, replaced) $\times 4$ (List: list 1 , list 2 , list 3, list 4) design.

Word data. As in the previous experiments, planned comparisons showed that the transposed-letter effect across morpheme boundaries was negligible $(-1 \mathrm{~ms})$, both $F \mathrm{~s}<1$; in contrast, when the letter transposition occurred within the stem of these same words, we found a $21-\mathrm{ms}$ facilitation effect, $F 1(1,28)=6.12, M S E=1133$; $F 2(1,80)=4.83, M S E=2820$ (the interaction between Position of manipulation $\times$ 
Table 3

Mean lexical decision times (in ms) and percentage of errors (in parentheses) for word targets in Experiment 3

\begin{tabular}{llll}
\hline & \multicolumn{2}{l}{ Type of prime } & Priming \\
\cline { 2 - 4 } & Transposed-letter & Replaced-letter & \\
\hline Word trials & $692(3.7)$ & $716(4.0)$ & $24(0.3)$ \\
$\quad$ Prefixed pairs (stem) & $713(4.3)$ & $714(2.8)$ & $1(-1.5)$ \\
Prefixed pairs (boundary) & $665(4.8)$ & $682(5.1)$ & $17(0.3)$ \\
Suffixed pairs (stem) & $675(4.0)$ & $673(4.5)$ & $-2(0.5)$ \\
Suffixed pairs (boundary) & $818(2.7)$ & $814(3.5)$ & $-4(0.8)$ \\
Nonword trials & & & \\
\hline
\end{tabular}

Type of prime was significant in the analysis by participants, $F 1(1,28)=5.46$, $M S E=912 ; F 2(1,80)=2.63, M S E=2122, p<.11)$. This interaction was similar in size for suffixed and prefixed words (see Table 3), as deduced from the lack of a significant Position of manipulation $\times$ Type of prime $\times$ Type of affix interaction (both $\left.F_{\mathrm{S}}<1\right)$. Finally, suffixed words, as a whole, were responded to faster than prefixed words, $F 1(1,28)=19.54, M S E=4007 ; F 2(1,80)=8.43, M S E=5655$. The other effects were not significant.

The ANOVAs on the error rates did not show any significant effects (all $p \mathrm{~s}>.21$ ).

Nonword data. None of the effects was significant.

The results of this experiment are straightforward. As in Experiments 1 and 2, the transposed-letter priming effect vanishes when the transposition of letters crosses the morpheme boundary. But the new finding is that the transposed-letter priming effect occurs for within-morpheme manipulations in the same set of prefixed and suffixed words (around $21 \mathrm{~ms}$ ). That is, the magnitude of the transposed-letter priming effect for monomorphemic words ( $21 \mathrm{~ms}$ in Experiment 2 ) is very similar to the magnitude of the transposed-letter priming effect for polymorphemic words when the letter transposition occurs within the stem.

\section{General discussion}

The present experiments replicate the well-known transposed-letter priming effect when the letter transpositions do not affect the morpheme boundaries (see Forster et al., 1987; Perea \& Lupker, 2003a, 2004). But the most remarkable finding is that the transposed-letter priming effect vanishes when the morphemic boundary is altered and this occurs both in an agglutinative and in a non-agglutinative language. Furthermore, the disappearance of the transposed-letter priming effect occurs when the transposition of letters crosses the morpheme boundaries of both prefixes and suffixes - note that the transposed-letter priming effect is robust when the manipulation involves the transposition of letters within the stem. Thus, the present set of data offers critical evidence for an early morphological decomposition process (see 
Christianson et al., 2005; Longtin \& Meunier, 2005; Longtin, Segui, \& Hallé, 2003; Rastle et al., 2004).

As indicated in Section 1, Christianson et al. (2005) showed a pre-lexical morphological decomposition on one of the multiple suffixes in English (-er) in a masked priming naming task. We have extended this finding not only to a large set of affixes (including prefixes and suffixes), but also to an agglutinative and a non-agglutinative language by using the standard lexical decision task. Accordingly, computational models of visual word recognition should echo this early morphological decoding. Rastle et al. (2004) recovered the proposals by Seidenberg (1987), who claimed for a frequency-based unit detection mechanism to explain this semantically blind decomposition process (see Brent, 1999; for a similar approach in speech perception). The idea is that the frequency of the bigrams and trigrams that constitute the morphemic boundary would be lower than the frequency of the bigrams and trigrams of the morpheme/affix. However, in the present experiments, the frequency of the critical bigram was controlled for Prime type in both affixed and non-affixed words (see also Christianson et al., 2005; or Rapp, 1992; for a similar criticism). More research is needed to clarify what kind of regularities (or patterns) the cognitive system uses as cues to perform morpho-orthographic decomposition during the early stages of visual word recognition (e.g., the frequency of the affix or frequency of the root, or, perhaps, some measure of morphological complexity such as the morphological family of the affix).

The dissociation of transposed-letter effects within vs. across morphemes also has important implications for the choice of an "input" coding scheme for visual word recognition. In the SOLAR model (Davis, 1999), letter assignment uses a spatial coding scheme in which the transposed-letter words trial and trail would activate the same letter nodes and are, therefore, perceptually similar (i.e., the first letter of the letter string is coded by the highest activity and all successive letters within the string are coded with progressively lower activities). This letter assignment process is posited to occur very early in processing, before morphological decomposition takes place: decomposition of any morphologically complex word is carried out only after one or more of the constituent morphemes are recognized in the lexicon (the segmentation-through-recognition hypothesis proposed by Davis, 1999). A similar reasoning applies to the overlap model (Gómez et al., submitted for publication). In this model, orthographic representations extend beyond their specific letter position into neighboring letter positions. The encoding activation of a given letter at a specific letter position is represented as a normal distribution with the peak of the curve falling at the correct letter position, independently of morphology. Thus, these models need to be modified to account for the vanishing transposed-letter effect across morphemes. One admittedly speculative option is that a morpheme detection mechanism is operative early in the process of visual word recognition, co-occurring with mechanisms responsible of assigning letter position. Morphological chunks, treated similarly to sole graphemes, would be recognized as a whole, co-occurring with to the letter position assignment. As affixes are short morphological chunks composed by a restricted number of letters - and with a high occurrence in the language - they could be recognized and segmented. In contrast, stems (as they are generally longer and more varied), would be decomposed in a letter-by-letter manner - note that this is consistent 
with the presence of transposed-letter effects across lexemes for compound words (Perea \& Carreiras, 2006a). Nonetheless, further research is needed to assess whether compounding necessarily predicts different processes of morphological decomposition than do derivation or inflection. In this light, one potential factor at work might be whether the transposed letters are adjacent or nonadjacent (see Christianson et al., 2005; vs. Perea \& Carreiras, 2006a): While Christianson et al. employed adjacent letter transpositions (e.g., ruwnay-RUNWAY), Perea and Carreiras used non-adjacent letter transpositions (always consonants; e.g., arbigide-ARGIBIDE; ARGIBIDE is a compound of $A R G I+B I D E$; light + way in English).

In summary, the present letter-transposition experiments add new empirical evidence to a growing body of data that suggests early morphological decomposition in lexical access, operating over some orthographic processes. Furthermore, this process seems to be language-independent: the vanishing transposed-letter priming effect across morphemes occurs for both agglutinative and non-agglutinative morphologies.

\section{Acknowledgments}

Jon Andoni Duñabeitia was the recipient of a post-graduate grant from the Basque Government. The research reported in this article has been partially supported by Grants SEJ2004-07680-C02-02/PSIC and SEJ2005-05205/EDU from the Spanish Ministry of Education and Science and BFF2002-10379-E from the ESFEUROCORES-OMLL. We thank Kathy Rastle and two anonymous reviewers for their constructive criticism on an earlier draft.

\section{References}

Andrews, S. (1996). Lexical retrieval and selection processes: effects of transposed-letter confusability. Journal of Memory and Language, 35, 775-800.

Brent, M. R. (1999). Speech segmentation and word discovery: a computational perspective. Trends in Cognitive Sciences, 3, 294-301.

Carreiras, M., Duñabeitia, J. A., \& Perea, M. (submitted for publication). The effects of transparency on morphological decomposition are language dependent.

Christianson, K., Johnson, R. L., \& Rayner, K. (2005). Letter transpositions within and across morphemes. Journal of Experimental Psychology: Learning, Memory, and Cognition, 31, 1327-1339.

Colé, P., Beauvillain, C., \& Segui, J. (1989). On the representation and processing of prefixed and suffixed derived words: a differential frequency effect. Journal of Memory and Language, 28, 1-13.

Coltheart, M., Rastle, K., Perry, C., Ziegler, J., \& Langdon, R. (2001). DRC: a dual-route cascaded model of visual word recognition and reading aloud. Psychological Review, 108, 204-256.

Davis, C. J. (1999). The Self-Organising Lexical Acquisition and Recognition (SOLAR) model of visual word recognition. Unpublished doctoral dissertation, University of New South Wales.

Forster, K. I., \& Forster, J. C. (2003). DMDX: a windows display program with millisecond accuracy. Behavior Research Methods, Instruments, \& Computers, 35, 116-124.

Giraudo, H., \& Grainger, J. (2001). Priming complex words: evidence for supralexical representation of morphology. Psychonomic Bulletin and Review, 8, 96-101.

Giraudo, H., \& Grainger, J. (2003). On the role of derivational affixes in recognizing complex words: evidence from masked priming. In R. H. Baayen \& R. Schreuder (Eds.), Morphological structure in language processing (pp. 209-232). Berlin: Mouton de Gruyter. 
Grainger, J., \& Jacobs, A. M. (1996). Orthographic processing in visual word recognition: a multiple readout model. Psychological Review, 103, 518-565.

Gómez, P., Ratcliff, R., \& Perea, M. (submitted for publication). The overlap model of the encoding of letter positions.

Laka, I. (1989). Constraints on sentence negation: the case of Basque. In I. Laka \& A. Mahajan (Eds.), Functional heads and clause structure. (Vol. 10, pp. 199-216). MIT Working Papers in Linguistics.

Longtin, CM., \& Meunier, F. (2005). Morphological decomposition in early visual word processing. Journal of Memory and Language, 53, 26-41.

Longtin, CM., Segui, J., \& Hallé, P. A. (2003). Morphological priming without morphological relationship. Language and Cognitive Processes, 18, 313-334.

Marslen-Wilson, W. D., Tyler, L. K., Waksler, R., \& Older, L. (1994). Morphology and meaning in the English mental lexicon. Psychological Review, 101, 3-33.

McClelland, J. L., \& Rumelhart, D. E. (1981). An interactive activation model of context effects in letter perception: Part 1. An account of basic findings. Psychological Review, 88, 375-407.

Meunier, F., \& Segui, J. (1999). Frequency effects in auditory word recognition: the case of suffixed words. Journal of Memory and Language, 41, 327-344.

Perea, M., \& Carreiras, M. (2006a). Do transposed-letter effects occur across lexeme boundaries? Psychonomic Bulletin and Review, 13, 418-422.

Perea, M., \& Carreiras, M. (2006b). Do transposed-letter similarity effects occur at a prelexical phonological level? Quarterly Journal of Experimental Psychology, 59, 1600-1613.

Perea, M., \& Lupker, S. J. (2003a). Does judge activate COURT? Transposed-letter similarity effects in masked associative priming. Memory \& Cognition, 31, 829-841.

Perea, M., \& Lupker, S. J. (2003b). Transposed-letter confusability effects in masked form priming. In S. Kinoshita \& S. J. Lupker (Eds.), Masked priming: State of the art (pp. 97-120). Hove, UK: Psychology Press.

Perea, M., \& Lupker, S. J. (2004). Can CANISO activate CASINO? Transposed-letter similarity effects with nonadjacent letter positions. Journal of Memory and Language, 57, 231-246.

Perea, M., Urkia, M., Davis, C. J., Agirre, A., Laseka, E., \& Carreiras, M. (in press). E-Hitz: a word-frequency list and a program for deriving psycholinguistic statistics in an agglutinative language (Basque). Behavior Research Methods.

Pollatsek, A., \& Well, A. (1995). On the use of counterbalanced designs in cognitive research: a suggestion for a better and more powerful analysis. Journal of Experimental Psychology: Learning, Memory, and Cognition, 21, 785-794.

Plaut, D. C., \& Gonnerman, L. M. (2000). Are non-semantic morphological effects incompatible with a distributed connectionist approach to lexical processing? Language and Cognitive Processes, 15, 445-485.

Rapp, B. (1992). The nature of sublexical orthographic organization: the bigram trough hypothesis examined. Journal of Memory and Language, 31,33-53.

Rastle, K., \& Davis, M. H. (2003). Reading morphologically complex words: some thoughts from masked priming. In S. Kinoshita \& S. J. Lupker (Eds.), Masked priming: State of the art (pp. 279-305). Hove, UK: Psychology Press.

Rastle, K., Davis, M. H., \& New, B. (2004). The broth in my brother's brothel: morpho-orthographic segmentation in visual word recognition. Psychonomic Bulletin and Review, 11, 1090-1098.

Rastle, K., Davis, M. H., Tyler, L. K., \& Marslen-Wilson, W. D. (2000). Morphological and semantic effects in visual word recognition: a time-course study. Language and Cognitive Processes, 15, 507-537.

Schoonbaert, S., \& Grainger, J. (2004). Letter position coding in printed word perception: effects of repeated and transposed letters. Language and Cognitive Processes, 19, 333-367.

Sebastián-Gallés, N., Martí, M. A., Carreiras, M., \& Cuetos, F. (2000). LEXESP: lexico informatizado del español. Barcelona: Edicions Universitat de Barcelona.

Seidenberg, M. S. (1987). Sublexical structures in visual word recognition: access units or orthographic redundancy? In M. Coltheart (Ed.), Attention and performance XII: The psychology of reading (pp. 245263). Hillsdale, NJ: Erlbaum.

Taft, M. (1994). Interactive-activation as a framework for understanding morphological processing. Language and Cognitive Processes, 9, 271-294. 